\title{
Estimating antemortem drug concentrations from postmortem blood samples: the influence of postmortem redistribution
}

\author{
D S Cook, R A Braithwaite, K A Hale
}

\begin{abstract}
Aims-To compare blood drug concentrations during life with postmortem drug concentrations measured from a peripheral site and a central site.

Methods-Coroner's cases from October 1990 to July 1997 were reviewed. Six cases had data on both antemortem and postmortem blood drug concentrations. The postmortem to antemortem ratio was compared with the postmortem central to peripheral ratio, using cardiac blood as a central site and femoral blood as a peripheral site.

Results-Drugs that have a high postmortem central to peripheral ratio; that is, drugs that exhibit considerable postmortem redistribution, also have high postmortem to antemortem ratios.

Conclusions-A large degree of error can arise from attempting to estimate antemortem drug concentrations and the ingested dose from postmortem measurements. The chosen site and technique for postmortem blood sampling can greatly influence the concentration of drug measured.

(F Clin Pathol 2000;53:282-285)
\end{abstract}

Keywords: postmortem blood sampling; drug concentrations; toxicological analysis

Postmortem drug redistribution refers to the processes by which the movement of drugs and other chemical poisons between tissues, organs, and body fluids takes place after death. This phenomenon is well recognised, and was first reported 25 years ago. ${ }^{1}$ Since then, considerable effort has gone into elucidating the processes responsible. ${ }^{2-16}$ Consideration of the redistribution of drugs is important in a variety of situations. Cases of suspected poisoning, either homicidal or suicidal; the role of drugs in "marginally toxic" cases, such as vehicle accidents; and also potential cases of euthanasia or medical negligence might rely upon the toxicological analysis of blood samples. ${ }^{2}$ The timing, method of collection, and source of the sample might influence the interpretation of toxicological analyses.

The processes of postmortem redistribution result in the migration of drugs between blood and tissues. The rate and extent of this movement varies according to several factors, including the nature of the drug and the time interval between death and postmortem specimen collection. Within the torso, the major organs constitute potential drug pools, and the gastrointestinal tract might contain considerable quantities of unabsorbed drug, and thus central blood is subject to redistribution from these local organs. Peripheral blood, such as femoral blood, is subject to redistribution influences only from local tissues-muscle and fat. In general, redistribution into central vessels is greater than redistribution into peripheral vessels. The difference between the two sites is known as the central to peripheral $(\mathrm{C} / \mathrm{P})$ ratio. For these reasons, the blood specimen of choice for toxicological analysis after death is a femoral venous sample, ideally collected from a ligated vessel, ${ }^{70}$ although inevitably there will be situations in which such sample collection is not possible.

Often, pathologists or toxicologists are requested to estimate the amount of drug present at the time of death, or the number of tablets consumed. This assumes that the drug concentration found at postmortem examination is a reliable estimate of that present at the time of death. There is a lack of evidence that such an extrapolation is possible; in only a few cases reported in the literature are antemortem blood concentrations available for comparison with values from a variety of sites at postmortem examination. ${ }^{14}{ }^{17-19}$ Such comparisons have not been carried out extensively because antemortem samples are often not available for analysis. In 1978, Vorpahl and $\mathrm{Coe}^{17}$ collected data pertaining to antemortem and postmortem blood digoxin concentrations. The chosen postmortem blood sampling site was the left ventricle. Their results showed that in all 27 cases, postmortem cardiac blood concentrations were significantly higher than antemortem blood concentrations. Blood from the femoral vein was only collected in 11 cases; in these cases, the average postmortem to antemortem (PM/AM) ratio was 1.4 , and in nine of the 11 cases the postmortem concentration was higher than the antemortem value.

Our paper comprises a series of brief case vignettes in which both antemortem and peripheral postmortem blood samples were analysed. The relation of the postmortem drug concentration to the antemortem concentration is investigated, and possible explanations for the variation seen are discussed in terms of postmortem redistribution.

\section{Methods}

We searched the coroner's archive of postmortem cases held at the regional laboratory for toxicology. The data were collected from October 1990 to July 1997, 950 cases in all. In six 
cases, both antemortem and postmortem blood samples labelled as "femoral blood" had been analysed, with data relating to seven drugs. All assays were performed on haemolysed whole blood with the use of internal quality assurance specimens for salicylate and paracetamol, and participation in NEQAS external quality assurance schemes for paracetamol, salicylate, amitriptyline, nortriptyline, and dothiepin. No internal or regular external quality assurance specimens were available for propranolol, methadone, and dextropropoxyphene during our study period. The methadone and dextropropoxyphene assays were validated by specimen exchange with other laboratories offering these analyses. In all cases except case 5, extensive drug screening was carried out. A review of the literature was also carried out to find reported $\mathrm{C} / \mathrm{P}$ ratios for these drugs. Where a $\mathrm{C} / \mathrm{P}$ ratio was not quoted in the literature, it was calculated for individual drugs from the central and peripheral postmortem blood concentrations determined for the case in question. In four of the cases (cases 2-5), the interval between antemortem sampling and death was known, and an estimate of the plasma concentration at the time of death was calculated using the following equation to account for the decline in drug concentrations as a result of ongoing metabolism and elimination during life ${ }^{17}$ :

$$
\ln \mathrm{N}_{\mathrm{t}}=\ln \mathrm{N}_{0}-\ln 2\left(\mathrm{~T} / \mathrm{t}_{\mathrm{t} / 2}\right)
$$

where: $\mathrm{N}_{\mathrm{t}}=$ calculated plasma drug concentration at time of death; $\mathrm{N}_{0}=$ plasma drug concentration at time of sampling; $\mathrm{T}=$ time interval between sampling and death; $\mathrm{t}_{1 / 2}=$ elimination half life of drug in plasma. ${ }^{20}$

\section{Case histories}

CASE 1

An 18 year old woman took an overdose of propranolol. She died shortly after admission to hospital; the postmortem examination was carried out on the next day. Propranolol was measured by means of reverse phase high performance liquid chromatography (HPLC) with ultraviolet (UV) detection.

CASE 2

A 22 year old man consumed a quantity of methadone mixture bought on the street. $\mathrm{He}$ was admitted unconscious to hospital and remained on life support for two days. Comprehensive drug screening for acidic, basic, and neutral drugs performed on an admission urine specimen detected only methadone and its major metabolite. Methadone was measured by means of reverse phase HPLC with UV detection.

CASE 3

A 74 year old man was admitted to hospital, having allegedly taken a paracetamol overdose. He died some 12 hours later. Paracetamol was assayed by means of an immunoassay (fluorescence polarisation immunoassay; Abbott Diagnostics, Abbott House, Maidenhead, Berkshire, UK). No other drugs were detected by screening capillary gas chromatography.
CASE 4

A 42 year old man was admitted after an overdose of dothiepin and distalgesic (paracetamol and dextropropoxyphene). He was maintained on a life support machine for one day. An antemortem blood sample was collected immediately before disconnection of this support. Both dothiepin and dextropropoxyphene were measured by means of reverse phase HPLC with UV detection, with simultaneous measurement of the major metabolites norpropoxyphene and nordothiepin.

\section{CASE 5}

A 28 year old woman was admitted having taken three overdoses of aspirin and Anadin in the previous three days. Antemortem blood was collected 4.3 hours before death. Salicylate was measured by colorimetry (Trinder's method). Quantitative immunoassay screening detected no tricyclic antidepressants.

\section{CASE 6}

A 41 year old woman was found unconscious having possibly taken an overdose of a friend's amitriptyline tablets. She was admitted to hospital but died the same day. Amitriptyline and nortriptylene were measured by means of reverse phase HPLC with UV detection. No other drugs were detected by screening capillary gas chromatography.

\section{Results}

Table 1 shows the data collected in the above cases. No further clinical, haematological, or biochemical data were available from the retrospective study of these cases.

The general trend of the data tabulated above is that drugs with a high $\mathrm{C} / \mathrm{P}$ ratio also tend to have a high PM/AM ratio. In these examples, propranolol is a notable exception, having a PM/AM ratio lower than the $\mathrm{C} / \mathrm{P}$ ratio. The elimination half life of propranolol is two to four hours. ${ }^{20}$ In the interval between antemortem sampling and death, continued metabolism of the drug will lower the circulating concentration. After four hours, in most individuals, the circulating concentration will be half that measured previously, if not lower. The time between sampling and death was not known in this patient. If the interval between sampling and death is of this order, or greater, then considerable overestimation of the drug concentration at death will result. Overestimation of the antemortem concentration will result in an artificially low PM/AM ratio.

Table 1 Comparison of postmortem peripheral blood (PM)/perimortem (AM) plasma ratios with C/P ratios for a selection of drugs

\begin{tabular}{lcll}
\hline Drug & $P M / A M$ & $C / P \ddagger$ & $C /$ P range \\
\hline Dothiepin & 11.7 & $2.2^{\star}$ & - \\
Dextropropoxyphene & 8.3 & 3.2 & $0.9-7.3$ \\
Amitriptyline & 3.9 & 2.9 & $0.9-13.9$ \\
Methadone & 2.6 & $2.6^{\star}$ & - \\
Propranolol & 1.9 & 2.5 & $1.0-3.8$ \\
Paracetamol & 1.5 & 1.3 & $0.7-2.8$ \\
Salicylate & 1.0 & 1.3 & $0.5-3.9$ \\
\hline
\end{tabular}

$\ddagger$ From Dalpe-Scott et al, 1995. ${ }^{21}$

${ }^{\star}$ Calculated from the specific case.

$\mathrm{C} / \mathrm{P}$, central to peripheral ratio. 


\section{Discussion}

These six cases illustrate that it can be dangerous to attempt to relate a drug concentration found at postmortem examination to the antemortem circulating concentration or to the antemortem dose received. In every case, the postmortem drug concentration in blood was as high as, or higher than, the antemortem circulating plasma drug concentration at the time of death. In several cases, the difference between the two concentrations was immense and cannot be accounted for by analytical error or differences in distribution of the drug between plasma and red blood cells. It is not possible to form a general rule regarding the difference between the two measurements, because the variation seen depends on the drug in question, as other authors have suggested.

The PM/AM ratios listed in the results table are all based on single case reports. It is possible that, if more cases were available, the PM/AM ratios found would be very different. The many factors that influence both $\mathrm{C} / \mathrm{P}$ and $\mathrm{PM} / \mathrm{AM}$ ratios, together with the wide variation of $\mathrm{C} / \mathrm{P}$ ratios documented, suggest that such variations might also be encountered in $\mathrm{PM} / \mathrm{AM}$ ratios. Thus, the PM/AM ratios listed cannot be applied in every case of death by these drugs.

In addition, other variables might influence the $\mathrm{C} / \mathrm{P}$ ratio, such as the interval between death and postmortem examination. This is a factor that has been shown to affect site specific postmortem drug concentrations to a great extent, ${ }^{16}$ and hence the $\mathrm{C} / \mathrm{P}$ ratio calculated. It is likely that this interval will also affect the PM/AM ratios calculated for these drugs, although drug concentrations in the femoral vein after death appear to be relatively stable with time, ${ }^{22} 23$ again making any extrapolation using these ratios unsafe.

Nonetheless, the trend of the data as a whole is striking. The finding that drugs exhibiting a high $\mathrm{C} / \mathrm{P}$ ratio tend to have a high $\mathrm{PM} / \mathrm{AM}$ ratio might prove useful in dealing with future cases in which poisoning may be a feature. The factors that influence postmortem redistribution are well established, and useful lists of $\mathrm{C} / \mathrm{P}$ ratios have been published by a number of authors. ${ }^{2124}$

It is often necessary to determine whether the drug concentration found at postmortem examination should be attributed to either therapeutic ingestion or overdose. This is very difficult to determine because of the influences of postmortem change. The use of PM/AM ratios, or back extrapolation from a postmortem concentration, is not recommended. For certain drugs, it may be more appropriate to consider the parent to metabolite ratio. It has been shown consistently for several drugs (for example, tricyclic antidepressants) that a high ratio is indicative of acute administration, as seen in overdose, because often in vivo metabolism is saturated or incomplete and circulating concentrations of the parent compound remain high. ${ }^{25-27}$ It is necessary to consider whether the parent compound and its more polar metabolites are subject to differing degrees of postmortem redistribution themselves, further confusing the issue.

The difficulties arising from postmortem redistribution must be put into the context of working practice. The development of a standardised protocol for toxicological sample collection at postmortem examination can assist both the pathologist and the toxicologist in their work. An important feature of such a protocol is its practicability. The chosen method must be easily incorporated into routine postmortem practice. Blood for quantitative analysis $(\approx 5 \mathrm{ml})$ should be taken from two distinct peripheral sites, preferably left and right femoral veins. Femoral blood can be taken by cutting the external iliac vein proximal to the inguinal ligament, and milking the distal cut end into the specimen tube. Early ligation of this vessel is recommended to avoid mixing with more central blood during evisceration. ${ }^{71028}$ An additional larger specimen of blood $(\approx 20 \mathrm{ml})$ for qualitative screening can be collected from a named convenient large vessel. For deaths that have occurred in hospital, the hospital pathology laboratory should be contacted as soon as possible to see if any antemortem specimens of urine, blood, or plasma are available, and these should also be sent for analysis.

Our study shows that a high degree of error can arise from attempting to predict antemortem concentrations from postmortem concentrations, and emphasises the need for continued research into this area of pathology practice. In the absence of such data, estimates of circulating drug concentrations during life should not be made. In borderline cases where drugs might be involved, the toxicological findings should only be used to support known clinical or pathological findings.

The work of Dr DS Cook was supported by a studentship grant from the Medical Research Council. Thanks to Professor GT Williams and Dr S Leadbeatter for their assistance in the preparation of this manuscript.

1 Gee DJ, Dalley RA, Green MA, et al. Post mortem diagnosis of barbiturate poisoning. In: Ballantyne B, ed. Forensic toxicology. Proceedings of a symposium held at the chemical defence establishment, Porton Down. Bristol: John Wright and Sons, 1972:37-51

2 Anderson WH, Prouty RW. Postmortem redistribution of drugs. In: Baselt RC, ed. Advances in analytical toxicology, Vol. 2. Chicago: Year Book Medical Publications, 1989:70102.

3 Hilberg T, Bugge A, Beylich K-M, et al. Postmortem changes of amitriptyline concentration in rats. In: Kaempe Proceting of the Associat

4 Hilberg T, Bugge A, Beylich K-M, et al. Diffusion as a mechanism of postmortem drug redistribution: an experimechanism of postmortem drug redistribution: an exp
mental study in rats. Int $\mathcal{F}$ Legal Med 1992;105:87-91.

5 Hilberg T, Bugge A, Beylich K-M, et al. An animal model of Hilberg T, Bugge A, Beylich K-M, et al. An animal model of
postmortem amitriptyline redistribution. $\mathcal{F}$ Forensic Sci

6 Hilberg T, Mørland J, Bjørneboe A. Postmortem release of amitriptyline from the lungs; a mechanism of postmortem drug redistribution. Forensic Sci Int 1994;64:47-55.

7 Jones GR, Pounder DJ. Site dependence of drug concentrations in postmortem blood-a case study. F Anal Toxicol 1987;11:186-90

8 Koren G, Klein J. Postmortem redistribution of morphine in rats. Ther Drug Monit 1992;14:461-3.

9 Mayer JM, Kofoed J, Robinson DW. Postmortem changes in drug concentrations in the blood. In: Jones GR, Singer PP, ds. Proceedings of the 24th international meeting of the Association of Forensic Toxicologists, Banff, Canada, 18-31 July 1987. Edmonton, Canada: Alberta Society of Clinical and
Forensic Toxicologists:40-7.

10 Pounder DJ. The nightmare of postmortem drug changes. In: Wecht CH, ed. Legal medicine 1993. Salem, New Hampshire: Butterworth Legal Publishers, 1994:163-91. 
11 Prouty RW, Anderson WH. Postmortem redistribution of drugs. In: Jones GR, Singer PP, eds. Proceedings of the 24th
international meeting of the Association of Forensic Toxicolointernational meeting of the Association of Forensic Toxicologists, Banff, Canada, 18-31 July 1987. Edmonton, Canada:
Alberta Society of Clinical and Forensic Toxicologists: Alberta

12 Pounder DJ, Davies JI. Zopiclone poisoning: tissue distribution and potential for postmortem diffusion. Forensic Sci Int 1994;65:177-83.

13 Pounder DJ, Hartley AK, Watmough PJ. Postmortem redistribution and degradation of dothiepin. Am f Forensic Med Pathol 1994;15:231-5.

14 Pounder DJ, Jones GR. Post-mortem drug redistribution-a toxicological nightmare. Forensic Sci Int 1990;45:253-63.

15 Rohrig TP, Harty LE. Postmortem distribution of mexiletine in a fatal overdose. f Anal Toxicol 1994;18:354-6.

16 Yonemitsu K, Pounder DJ. Temporal changes in postmortem drug levels in co-proxamol poisoning. In: Kaempe $\mathrm{B}$, ed. Proceedings of the 29th international meeting of the Association of Forensic Toxicologists, Copenhagen, 1991: Association

17 Vorpahi TE, Coe JI. Correlation of antemortem and postmortem digoxin levels. I Forensic Sci 1978;23

18 Jones GR. Postmortem changes in drug levels: a common phenomenon? In: Heyndrickx B, ed. Proceedings of the 23rd international meeting of the Association of Forensic Toxicologists, Ghent, Belgium. International Association of Forensic Toxicologists, 1986:29-35.

19 O'Sullivan JJ, McCarthy PT, Wren C. Differences in amiodarone, digoxin, flecainide and sotolol concentrations between antemortem serum and femoral postmortem blood. Hum Exp Toxicol 1995;14:605-8.
20 Baselt RC, Cravey RH. Disposition of toxic drugs and chemicals in man, 4 th ed. California: Chemical Toxicology chemicals in man
Institute, 1995.

21 Dalpe-Scott M, Degouffe M, Garbutt D, et al. A comparison of drug concentrations post mortem cardiac and peripheral blood in 320 cases. Fournal of Canadian Society of Forensic Science 1995;28:113-21.

22 Gomez HF, McKinney P, Phillips S, et al. Postmortem acetaminophen pharmacokinetics: an experimental study of site and time-dependent concentration changes. F Forensic Sci 1995;40:980-2.

23 Martin A, Pounder DJ. Post-mortem toxico-kinetics of trazodone. Forensic Sci Int 1992;56:201-7.

24 Péclet C, Picotte P, Rousseau JJ, et al. Post-mortem release phenomenon: a study of blood levels in 121 cases of drug related deaths. In: Jones GR, Singer PP, eds. Proceedings of the 24th international meeting of the Association of Forensic Toxicologists, Banff, Canada, 18-31 July 1987. Edmonton, Canada: Alberta Society of Clinical and Forensic Toxicologists: 22-31.

25 Bailey DN, Van Dyke C, Langou RA, et al. Tricyclic antidepressants: plasma levels and clinical findings in overantidepressants: plasma levels and clinica
dose. Am f Psychiatry 1978;135:1325-8.

26 Bailey DN, Shaw RF. Interpretation of blood and tissue concentrations in fatal self-ingested overdose involving amitriptyline: an update (1978-1979). F Anal Toxicol 1980; 4:232-6.

27 Apple FS. Postmortem tricyclic antidepressant concentrations: assessing cause of death using parent drug to metabolite ratio. F Anal Toxicol 1989;13:197-8.

28 Skopp G, Lutz R, Ganâmann R, et al. Postmortem distribution pattern of morphine and morphine glucuronides in heroin overdose. Leg Med 1996;109:118-24. 